\title{
EFFECT OF WI-FI RADIOFREQUENCIES ON THE CONTENT OF FATTY ACID AND ERGOSTEROL, A PRECURSOR OF VITAMIN D, IN IN VITRO CULTURES OF THE FUNGUS Serpula himantioides
}

\author{
GABRIELA OYARCE ${ }^{a}$, GASTÓN BRAVO-ARREPOL $^{a}$, SERGIO TRIVIÑO ${ }^{a}$, FLAVIO NANCO $^{a}$, \\ RODRIGO HASBÚN ${ }^{b}$, CLAUDIA PÉREZ ${ }^{a}$, JOSÉ BECERRA ${ }^{a}$ AND SOLANGE TORRES ${ }^{a^{*}}$ \\ ${ }^{a}$ Laboratorio de Química de Productos Naturales, Facultad de Ciencias Naturales y Oceanográficas, Departamento de Botánica, \\ Universidad de Concepción, Chile. \\ ${ }^{b}$ Laboratorio de Epigenética Vegetal, Facultad de Ciencias Forestales, Departamento de Silvicultura, Universidad de Concepción, Chile.
}

\begin{abstract}
In the microwave-radiofrequency spectrum, Wi-Fi is a short-range wireless broadband technology, which transmits at a frequency of $2.5 \mathrm{GHz}$. This type of technology has been positioned itself as one of the most widely used technological advances in recent years. It has been reported that direct exposition to radiofrequencies can induce physiological changes in different animals and plants species. One of the degenerative effects that Wi-Fi can cause is the production of reactive oxygen species, inducing tissue damage and DNA alterations. In fungi, the effect of exposure to electromagnetic radiation in the UV spectrum has been extensively studied, the physiological effect to radiofrequencies such as Wi-Fi is unknown. In that sense, the aim of this study was to detect the main changes in metabolism of some acid fatty and ergosterol of the fungus Serpula himantioides, using gas chromatography - mass spectrometry (GC-MS), and evaluate the antioxidant activity of metabolites obtained from in vitro cultures of $S$. himantioides exposed to Wi-Fi at $2.5 \mathrm{GHz}$. The results showed an increment in the content of some the fatty acids and ergosterol, in total extracts from the fungus mycelium. Antioxidant analysis revealed that the total extracts of $S$. himantioides culture medium showed antioxidant capacity associated with an increment in the content of phenolic compounds. Our results suggest that direct exposition to Wi-Fi radiation produces oxidative damage by modifying cellular components in the fungus $S$. himantioides.
\end{abstract}

Keywords: Serpula himantioides, radiofrequencies Wi-Fi, metabolites, antioxidant activity.

\section{INTRODUCTION}

Organisms are subjected to different stress factors, such as temperature, availability of water and radiation can generate changes in morphology, enzyme activation and the accumulation of certain groups of secondary metabolites [1]. A factor that has become important in recent years is high-frequency electromagnetic fields (HF-EMF). These are radiations that are in the frequency range between $300 \mathrm{MHz}$ to $100 \mathrm{GHz}$ and are emitted within the range of bands of the Radiofrequency-Microwave (RF-MI). These non-ionizing electromagnetic radiations are absorbed at the molecular level and manifested through changes in the vibrational energy of the molecules or heat [2]. At present, the level of exposure to electromagnetic radiation has increased with the development and massification of wireless communication technologies [3]. In the case of Wi-Fi radio frequencies, it is a short-range wireless broadband technology in the range of $2.4 \mathrm{GHz}$ and $5.0 \mathrm{GHz}$ with a broad effect on biological systems [4].

Direct exposure to radio frequencies can induce changes in cell physiological processes in living organisms [5]. Some of the degenerative effects involve reactive oxygen species (ROS) production, which contributes to tissue and DNA damage [6,7]. In studies carried out in mice, the exposures to RF-MI of $2.45 \mathrm{GHz}$ causes an increase in the level of peroxidation in lipids and a decrease of the enzymatic activity associated with the prevention and protection of these [8]. In plants, it has been reported that exposure of 2 hours to the $23 \mathrm{~V} / \mathrm{m}$ electric field of $900 \mathrm{MHz}$ significantly decreased the growth of Lemna minor L plants [9]. Furthermore, within the same study, changes were observed in the activity of the peroxidase enzyme, which plays an essential role in the development of the plants and are used as a biomarker in plants subjected to stress [10-14].

Regarding the possible effect of this type of radiation on fungi, no studies have been reported. However, in other types of electromagnetic radiation, such as UV, it has been reported the induction of sporulation and growth in fungi [15-17]. A recent study in in vitro culture of Serpula himantioides (Fr.) P. Karst. at different intensities of UV radiation, showed an increase in the synthesis and accumulation of phenolic pigments in the cell wall to protect the hyphal cell from the penetration of UV radiation into more internal compartments of the cell [18]. S. himantioides is a saprophytic fungus that belongs to the Conioforaceae family, constituting the Boletales order, it has a wide geographical distribution, where it predominates in temperate zones of Europe and America, growing on dead coniferous wood, producing an intensive brown rot. This fungus produces thin, resupinate and brownish colored annual basidiocarps [19-21].
Since the possible effect of Wi-Fi radiation on the metabolism of fungi has not been studied, the aim of the present study was to evaluate the effect of Wi-Fi radiation on the content of physiologically active compounds from in vitro cultures of Serpula himantioides.

\section{EXPERIMENTAL}

\subsection{General}

Culture media Potato Dextrose Broth (PDB) was purchased from BD Difco ${ }^{\mathrm{TM}}$. Solvents used in this study such as methanol and ethyl acetate were distilled prior to use and obtained from Merck (Darmstadt, Germany). Standards of fatty acids and ergosterol were also obtained from Merck (Darmstadt, Germany). 2,2-azinobis(3-ethylbenzothiazoline-6-sulfonic acid) diammonium salt (ABTS), 6hydroxy- 2,5,7,8-tetramethylchromane-2-carboxylic acid (Trolox) and 2,2diphenyl-1-picrylhydrazyl (DPPH) were purchased from Sigma-Aldrich. Potassium persulfate $\left(\mathrm{K}_{2} \mathrm{~S}_{2} \mathrm{O}_{8}\right)$ was purchased from Merck (Darmstadt, Germany). Milli-Q-grade water was used during the entire process.

\subsection{Isolation of biological material}

Basidiomes of Serpula himantioides that were found growing on decaying conifer wood in the Native Forest of the Bíobío region (Chile Central Zone) $\left(36^{\circ}\right.$ $\left.50^{\prime} 15^{\prime \prime} \mathrm{S}, 73^{\circ} 01^{\prime} 30^{\prime \prime} \mathrm{W}\right)$. For the recognition of the collected material, both macroscopic and microscopic characteristics were studied together with specialized mycological bibliography. The reference material has been deposited in the fungal collection at the Universidad de Concepción (accession number CONC-F 1792) [18].

\subsection{In vitro growth conditions}

From the material previously isolated in petri dishes, the in vitro culture of $S$. himantioides using potato dextrose broth (PDB) as a liquid culture medium in 1L flasks were prepared. Two study groups in parallel were considered $[22,23]$. The Figure 1 shows the schematic diagram of the Wi-Fi exposure system. A control group that was kept in darkness with temperature and humidity controlled, without antenna and constituted by three flasks, and a treatment group, which also remained under the same conditions of temperature, humidity and darkness, inside a growth chamber indoor type with antenna (Cropbox Propagator $50 \times 80 \times 50 \mathrm{~cm})$. The exposure to radiation was made for five weeks. 
The record of the variations of temperature and humidity for the control and Wi-Fi radiation treatment were taken.

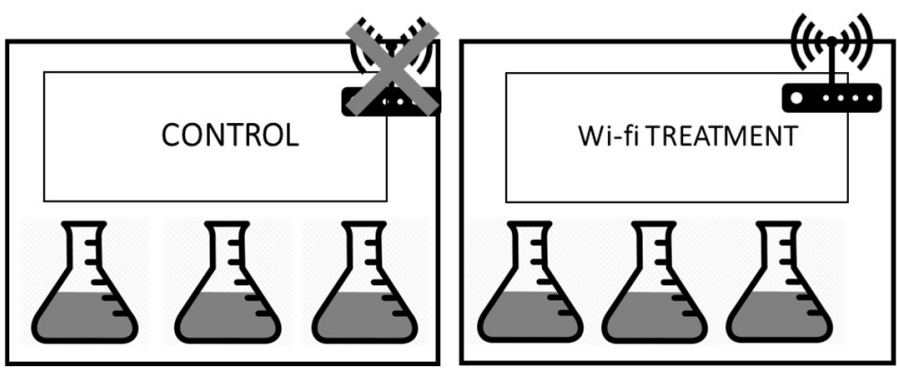

Figure 1. Outline of the experiment, considering the control, without any type of antenna that emits radiation. The treatment subjected to the Wi-Fi radiation, at the frequency of $2.5 \mathrm{GHz}$.

\subsection{Exposure of mycelial cultures to $\mathrm{Wi}-\mathrm{Fi}$}

For the exposure of mycelial liquid cultures to Wi-Fi radiation, a frequency of $2.45 \mathrm{GHz}$ was considered. For this, the Wi-Fi NanoStation 2 antenna $(2.4 \mathrm{GHz}$, $10 \mathrm{dBi}$, Ubiquiti Networks, Inc. USA) was used to issue the radiation as previously reported [24]. The flasks were in close contact with the antenna (a maximum distance was $40 \mathrm{~cm}$ ). The treatment was maintained for five weeks, and from the third week the radiation was applied continuously.

The measurement of radiation and noise power $(\mathrm{dBm})$ were taken from the third week of culture, once a day until the fifth week, using the NanoStation locoM2 antenna (Ubiquiti Networks, Inc. USA). The Airview software Ubiquiti Samples were taken at seven days of exposure and at the end of this, all measurements were averaged and the value in power density $\left(\mathrm{mW} / \mathrm{cm}^{2}\right)$ was taken. The average power and noise in $\mathrm{dBm}$ were expressed as previously described [25].

Table 1. Radiation media with their respective standard deviations used in the study group.

\begin{tabular}{|c|c|c|}
\hline Potency media $(\mathbf{d B m})$ & Potency density $\left(\mathbf{m w} / \mathbf{c m}^{2}\right)$ & Noise $(\mathbf{d B m})$ \\
\hline$-3.75( \pm 5.092)$ & $4.217 \times 10^{-5}$ & $-97.38( \pm 0.518)$ \\
\hline
\end{tabular}

\subsection{Total extracts obtention}

The liquid cultures were filtered to separate the mycelium from the culture broth, at the end of the incubation period. The mycelium was vacuum dehydrated with a lyophilizer and then extracted with methanol (1:1 methanolic extract), and the broth culture was extracted with ethyl acetate (extract of ethyl acetate). Both total extracts were concentrated to dryness in a rotating evaporator and stored at $4{ }^{\circ} \mathrm{C} .10 \mathrm{mg} / \mathrm{mL}$ of extracts were used for quantitative analysis.

2.6. Chemical analysis by gas chromatography coupled to mass spectrometry (GC-MS)

The GC-MS analysis of underivatized the total extracts obtained from both the mycelium and the culture medium was carried out on a gas chromatograph (Agilent $7890 \mathrm{~A})$ with a splitless injector $\left(250^{\circ} \mathrm{C}\right.$ ) and a mass detector (Agilent 5975C). A HP-5MS capillary column $(30 \mathrm{~m} \times 0.25 \mathrm{~mm} \times 0.25 \mu \mathrm{m})$ and helium gas (constant flow $1 \mathrm{~mL} / \mathrm{min}$ ) were used for separation. The temperature program was: $5 \mathrm{~min}$ hold at $100{ }^{\circ} \mathrm{C}, 100-275^{\circ} \mathrm{C}$ at $13{ }^{\circ} \mathrm{C} / \mathrm{min}$ and $32 \mathrm{~min}$ hold at $275^{\circ} \mathrm{C}$. Detection range was $\mathrm{m} / \mathrm{z} 50-550$. The injector temperature was $250^{\circ} \mathrm{C}$. Tentative identification of the components was accomplished by matching mass spectra to records in the NIST 05 (NIST/EPA/NIH Mass Spectral Library 2005) and by comparing the obtained spectra with those reported in the literature.

NIST 05 collects representative fatty acid and ergosterol of all the skeletons referenced. The structure of a compound is tentatively assigned when the overlap with the database exceeds $90 \%$. For the quantification of the fatty acids, a calibration curve was made with the eicosanoic acid standard acquired from Merck (99\% purity), where from the equation of the calculated straight line, the concentration of the fatty acids was obtained $(\mu \mathrm{g} / \mathrm{mL})$, and for the quantification of ergosterol, a calibration curve was made of the internal standard of tetracosine, where the ergosterol concentration was obtained $(\mu \mathrm{g} / \mathrm{mL})$.

\subsection{Antioxidant activity}

2.7.1. Estimation of radical scavenging activity using the DPPH (2,2diphenyl-1-picrylhydrazyl) assay.

The radical scavenging activity of the extracts from mycelium and culture broth were examined with DPPH (2,2-diphenyl-1-picrylhydrazyl) radical, as described previously [26]. A sample stock solution $(2000 \mu \mathrm{g} / \mathrm{mL})$ was diluted with methanol to different final concentrations $(1000,800,600,400,200$ and 100 $\mu \mathrm{g} / \mathrm{mL})$. After this, an aliquot of $20 \mu \mathrm{L}$ was taken for each dilution and $180 \mu \mathrm{L}$ of methanolic solution of DPPH $\left(6 \times 10^{-5} \mathrm{~mol} / \mathrm{L}\right)$, were deposited in a 96-well clear microplate and the mixture was kept for 30 minutes to darkness.

The reduction of the DPPH radical was determined by measuring its absorption at $515 \mathrm{~nm}$ using an ELX800 microplate reader (BioTek Instruments, Inc., Winooski, VT) and the antioxidant activity was calculated as the percentage of radical scavenging activity (RSA) of DPPH, given by its discoloration, with the following equation:

$$
\text { RSA of DPPH }(\%)=[(\text { Acontrol }- \text { Asample }) / \text { Acontrol }] x 100
$$

Where Acontrol is the absorbance of methanolic DPPH whereas Asample corresponds to the absorbance of the extract solution. The measurements were performed at $20^{\circ} \mathrm{C}$ and the experiment was carried out in triplicate and the antioxidant activity curve of the Trolox (6-hydroxy-2,5,7,8tetramethylchromane-2-carboxylic acid) reagent was used as a positive control [26].

\subsubsection{Antioxidant capacity using ABTS (2,2'-azino-bis (3-} ethylbenzothiazoline-6-sulphonic acid) assay.

The radical scavenging activity of the extracts from mycelium and culture broth were evaluated using ABTS (2,2'-Azino-bis(3-ethylbenzothiazoline-6sulfonic acid) diammonium salt) assay, as described previously [27]. A sample stock solution $(2000 \mu \mathrm{g} / \mathrm{mL})$ was diluted with methanol to different final concentrations $(1000,800,600,400,200$ and $100 \mu \mathrm{g} / \mathrm{mL})$. The radical was generated by the reaction of $0.375 \mathrm{~mol} / \mathrm{L}$ ABTS in water with $1,225 \times 10^{-3} \mathrm{~mol} / \mathrm{L}$ potassium persulfate (1:1, final concentration). $20 \mu \mathrm{L}$ of methanolic extracts of different concentrations of samples were mixed with $180 \mu \mathrm{L}$ of ABTS radical solution.

The reduction of the ABTS radical was determined by measuring its absorption at $750 \mathrm{~nm}$ using an ELX800 microplate reader (BioTek Instruments,Inc., Winooski, VT) and the antioxidant activity was calculated as the percentage of radical scavenging activity (RSA) of ABTS, given by its discoloration, with the following equation:

$$
\text { RSA of ABTS }(\%)=[(\text { Acontrol }- \text { Asample }) / \text { Acontrol }] x 100
$$

Where Acontrol is the absorbance of methanolic ABTS whereas Asample corresponds to the absorbance of the extract solution. The measurements were performed at $20^{\circ} \mathrm{C}$ and the experiment was carried out in triplicate. Trolox reagent was used as the standard.

\subsection{Total phenolic content}

Total phenolic content (TPC) was determined using Folin-Ciocalteau (FC) reagent according to the procedure described previously [28]. $1 \mathrm{~mL}$ of each extract was mixed with $1 \mathrm{~mL}$ of FC (diluted with distilled water, 1:10) for $90 \mathrm{~min}$ at room temperate $\left(20 \pm 1^{\circ} \mathrm{C}\right) .1 \mathrm{~mL}$ of saturated sodium carbonate solution was added and then the mixture was adjusted to $10 \mathrm{~mL}$ with distilled water and kept at room temperature in the dark for 90 minutes. The absorbance of the resulting blue color was measured at $750 \mathrm{~nm}$ using an ELX800 microplate reader (BioTek Instruments,Inc., Winooski, VT). The TPC was determined as gallic acid equivalent (GAE) on a dry-weight basis (milligrams GAE per gram of extract) using a calibration curve established $(0-100 \mu \mathrm{g} / \mathrm{mL})$ gallic acid standards using a similar procedure. The measurements were performed in triplicate.

\subsection{Statistic analysis}

The data were analyzed through the t-test with an $\alpha=0.05$, and the Fisher LSD

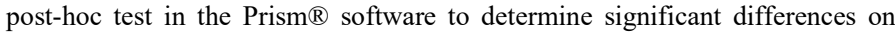
compounds identified for control and treatment. The analysis of antioxidant 
capacity for each extract was carried out in triplicate and the results were expressed as a function of the standard deviation (SD). The data were analyzed through the two-way ANOVA test with $\alpha=0.05$, and the Fisher LSD post-hoc test. Moreover, for the total phenolic content, the data were analyzed through ttest, with $\alpha=0.05$, in the Prism ${ }^{\circledR}$ software.

\section{RESULTS AND DISCUSSION}

\subsection{Content of some fatty acids in $S$. himantioides}

The present research work focused on evaluate the main changes in the metabolism of the $S$. himantioides. In the extract from mycelium exposed during 7 days to Wi-Fi radiation, a significant decrease in stearic acid $(128.96 \pm 13.1$ to $63.61 \pm 8.1)$ and an increase in palmitic (saturated) $(5.50 \pm 2.2$ to $42.45 \pm 5.3)$ and linoleic (unsaturated) acid was observed $(22.54 \pm 6.7$ to $121.66 \pm 4.6)$ with respect to the control (Figure 2).

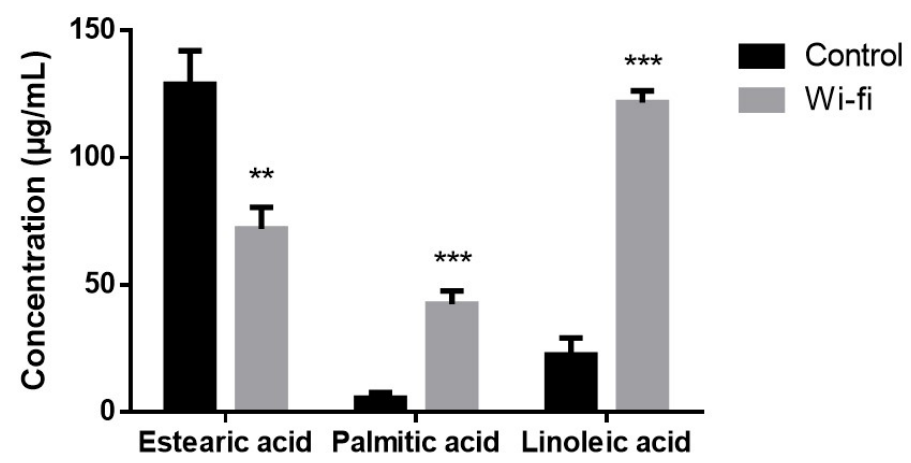

Figure 2. Fatty acids detected in Serpula himantioides extracts, through GCMS analysis at 7 days of exposure to Wi-Fi radiation. The significant differences concerning the control are indicated by $* *(\mathrm{p}<0.05),{ }^{* * *}(\mathrm{p}<0.0001)$ with test-t.

In order to maintain optimal membrane fluidity for normal cell function organisms such as plants and animals regulate the composition of their lipid membrane in response to ambient temperature in order to maintain optimal membrane fluidity for normal cell function [29]. In microorganisms such as yeasts, an increase in ambient temperature leads to an increase in the degree of saturation of the lipid membranes [30]. An increase in the content of fatty acids in different species of yeast, in particular palmitic acid and linoleic acid, when subjected to high temperatures was previously reported [30].

This could explain the increase in the concentration of saturated fatty acids obtained in the present study for $S$. himantioides. HF-EMF are radiations that are classified as non-ionizing, however, they can cause an increase in the temperature of biological material associated with changes in the permeability of the cell membrane $[9,31,32]$.

\subsection{Ergosterol content in the extract from the mycelium of $S$. himantioides}

For the extract from the mycelium exposed to Wi-Fi radiation, an increase in the signal intensity for the compound ergosterol was observed, compared to control (Figure 3). These differences were significant, with an increase of 7 times the concentration of the ergosterol compound when exposed to Wi-Fi (Table 2).

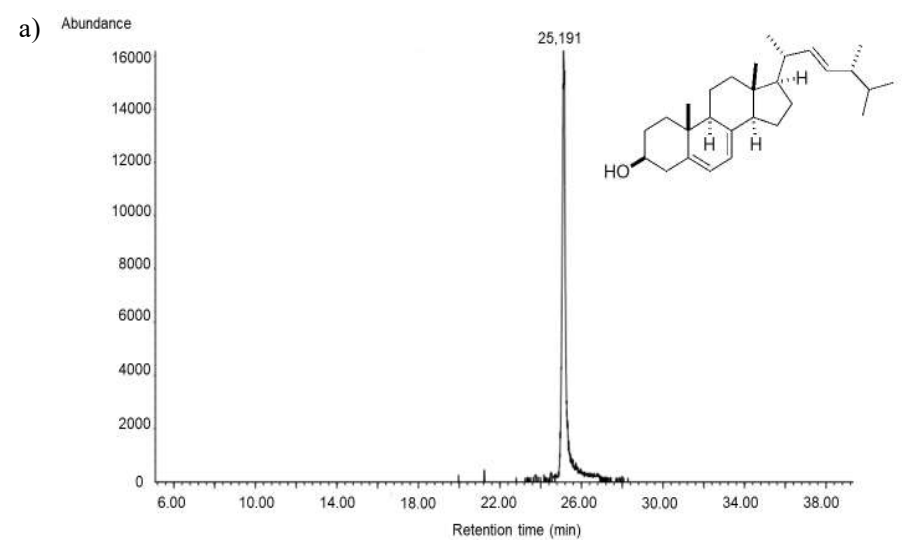

b) Abundance

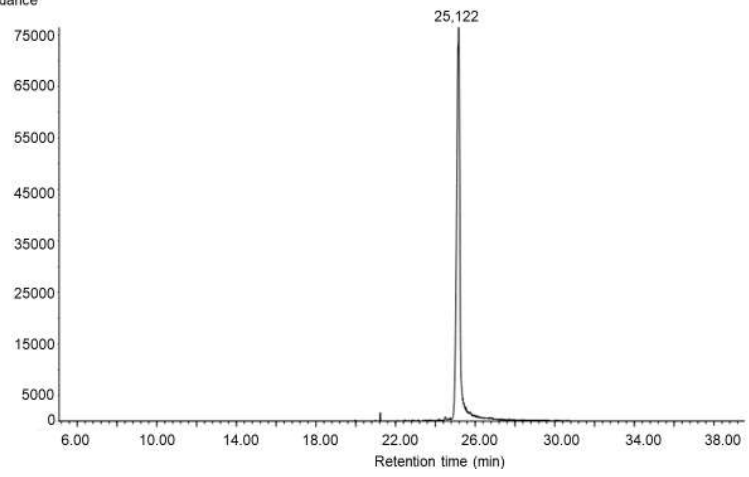

Figure 3. Chromatogram of the mycelium extract from the control (A) and mycelium extract with Wi-Fi treatment (B) at the same concentration (10 $\mathrm{mg} / \mathrm{mL}$ ). An ion extraction was performed at $396 \mathrm{~m} / \mathrm{z}$ to visualize only the compound ergosterol.

Table 2. Concentration of ergosterol expressed in $\mathrm{mg} / 100 \mathrm{mg}$ of dry mycelium, obtained from the mycelium extract of $S$. himantioides exposed to Wi-Fi radiation.

\begin{tabular}{|c|c|}
\hline \multicolumn{2}{|c|}{ Ergosterol content (mg/100 mg of mycelium extract) } \\
\hline Control & Treatment \\
\hline $0.400 \pm 0.17$ & $2.577 \pm 0.14(* * *)$ \\
\hline
\end{tabular}

$(* * *) \mathrm{p}<0.001$ with the test-t.

Ergosterol (Figure 3) is a type of sterol found mainly in fungi whose principal function is to contribute to the structure and dynamic state of the plasma membrane, in addition to regulating the permeability of the membrane to changes in environmental conditions [33].

Different studies [34-36] that have studied the behavior of ergosterol under UV-B radiation, observing an increase of this, because photolysis of the molecule occurs that gives rise to a variety of photoirradiated products, mainly being found precursors of vitamin D, tachisterol and lumisterol [37]. As proposed by [38], exposure to UV-B radiation is an effective way to increase the vitamin D content in mushrooms, giving a direct relationship between higher radiation doses and a higher concentration of the vitamin in Agaricus bisporus and Lentinus edodes.

On the other hand, mushrooms are the only non-animal source of this type of vitamin. These are usually found in low concentrations $[34,39,40]$ so the search for new alternatives to increase their content becomes necessary, being the exposure to Wi-Fi radiation, a choice to stimulate the production of this vitamin in edible mushrooms.

\subsection{Antioxidants assays}

There is an increase in the antioxidant activity of the treatment exposed to WiFi radiation for both the DPPH (Table 3) and ABTS (Table 4) assays as the concentration was increased. In addition, the highest percentages of radical inhibition were reported in the culture medium for both assays.

Table 3. DPPH radical reduction activity of Serpula himantioides extracts.

\begin{tabular}{|l|c|c|c|c|c|}
\hline \multicolumn{5}{|c|}{ Percentage of Inhibition of radicals at different concentrations $(\boldsymbol{\mu g} / \mathbf{m L})$} \\
\hline \multicolumn{1}{|c|}{ Extracts } & $\mathbf{1 0 0 0}$ & $\mathbf{8 0 0}$ & $\mathbf{6 0 0}$ & $\mathbf{2 0 0}$ & $\mathbf{1 0 0}$ \\
\hline $\begin{array}{l}\text { Mycelium } \\
\text { control }\end{array}$ & $20.27 \pm 0.7^{\mathrm{Ba}}$ & $17.37 \pm 0.51^{\mathrm{Bb}}$ & $14.35 \pm 0.2^{\mathrm{Bc}}$ & $5.98 \pm 1.4^{\mathrm{Bd}}$ & $1.843 \pm 0.2^{\mathrm{Bd}}$ \\
\hline $\begin{array}{l}\text { Mycelium } \\
+W i-F i\end{array}$ & $23.95 \pm 0.3^{\mathrm{Aa}}$ & $20.72 \pm 2.7^{\mathrm{Ab}}$ & $18.26 \pm 1.7^{\mathrm{Ac}}$ & $9.55 \pm 2.0^{\mathrm{Ad}}$ & $8.88 \pm 1.0^{\mathrm{Ad}}$ \\
\hline $\begin{array}{l}\text { Culture broth } \\
\text { control }\end{array}$ & $50.92 \pm 3.9^{\mathrm{Ba}}$ & $44.56 \pm 3.9^{\mathrm{Bb}}$ & $35.85 \pm 4.5^{\mathrm{Bc}}$ & $16.92 \pm 3.0^{\mathrm{Ad}}$ & $12.90 \pm 1.7^{\mathrm{Ae}}$ \\
\hline $\begin{array}{l}\text { Culture broth } \\
+W i-F i\end{array}$ & $59.46 \pm 2.8^{\mathrm{Aa}}$ & $57.12 \pm 1.3^{\mathrm{Ab}}$ & $39.03 \pm 0.3^{\mathrm{Ac}}$ & $16.75 \pm 2.2^{\mathrm{Ad}}$ & $13.02 \pm 2.5^{\mathrm{Ae}}$ \\
\hline
\end{tabular}

Percentages with the same letters are not significantly different from each other $(\mathrm{p}>0.05)$. Means with the same letter are not significantly different from each other $(\mathrm{p}>0.05)$. 
Table 4. ABTS radical reduction activity of Serpula himantioides extracts.

\begin{tabular}{|l|c|c|c|c|c|}
\hline \multicolumn{5}{|c|}{ Percentage of inhibition of radicals at different concentrations $(\boldsymbol{\mu g} / \mathbf{m L})$} \\
\hline Extracts & $\mathbf{1 0 0 0}$ & $\mathbf{8 0 0}$ & $\mathbf{6 0 0}$ & $\mathbf{2 0 0}$ & $\mathbf{1 0 0}$ \\
\hline $\begin{array}{l}\text { Mycelium } \\
\text { control }\end{array}$ & $31.73 \pm 0.5^{\mathrm{Ba}}$ & $28.37 \pm 0.7^{\mathrm{Bb}}$ & $22.02 \pm 1.0^{\mathrm{Bc}}$ & $13.02 \pm 3.8^{\mathrm{Ad}}$ & $7.51 \pm 0.5^{\mathrm{Ae}}$ \\
\hline $\begin{array}{l}\text { Mycelium } \\
+W i-F i\end{array}$ & $39.79 \pm 0.8^{\mathrm{Aa}}$ & $36.26 \pm 0.8^{\mathrm{Ab}}$ & $29.03 \pm 1.1^{\mathrm{Ac}}$ & $14.57 \pm 2.8^{\mathrm{Ad}}$ & $9.22 \pm 1.0^{\mathrm{Ae}}$ \\
\hline $\begin{array}{l}\text { Culture broth } \\
\text { control }\end{array}$ & $84.44 \pm 2.1^{\mathrm{Ba}}$ & $80.08 \pm 0.2^{\mathrm{Bb}}$ & $66.18 \pm 1.8^{\mathrm{Ac}}$ & $31.76 \pm 0.6^{\mathrm{Ad}}$ & $21.66 \pm 1.3^{\mathrm{Ae}}$ \\
\hline $\begin{array}{l}\text { Culture broth } \\
+W i-F i\end{array}$ & $89.35 \pm 0.8^{\mathrm{Aa}}$ & $85.71 \pm 1.5^{\mathrm{Ab}}$ & $59.23 \pm 1.8^{\mathrm{Bc}}$ & $32.48 \pm 0.5^{\mathrm{Bd}}$ & $19.56 \pm 0.4^{\mathrm{Be}}$ \\
\hline
\end{tabular}

Percentages with the same letters are not significantly different from each other( $\mathrm{p}>0.05)$. Means with the same letter are not significantly different from each other $(\mathrm{p}>0.05)$.

Table 5. Total phenolic content reported in the culture media extract and mycelium exposed to Wi-Fi radiation.

\begin{tabular}{|c|c|}
\hline Extracts & Total phenolic content GAE (mg/g of extract) \\
\hline Culture broth control & $386.7 \pm 11.5$ \\
\hline Culture broth $+\mathrm{Wi}-\mathrm{Fi}$ & $490 \pm 0^{*}$ \\
\hline Mycelium control & $510 \pm 10^{\text {ns }}$ \\
\hline Mycelium + Wi-Fi & $500 \pm 17.3$ \\
\hline
\end{tabular}

(*) $\mathrm{p}<0.005$ with test-t.

An increase in antioxidant activity was observed in mycelium extracts and culture media subjected to Wi-Fi radiation. For the ABTS assay the extract from the culture medium was reported with the highest values of free radical inhibition, reaching $89 \%$ inhibition at $1000 \mu \mathrm{g} / \mathrm{mL}$. While for the extracts obtained from mycelium the percentages of inhibition did not exceed $40 \%$ in any of the assays.

On the other hand, regarding the total phenolic content (Table 5), a significant difference was observed in culture medium exposed to Wi-Fi radiation, compared to the control, which would indicate a greater abundance of phenolic compounds, which is consistent with what was observed with the antioxidant activity.

In Vigna radiata (L.) plants exposed to $900 \mathrm{MHz}$ radio frequencies, an increase in antioxidant activity was observed, given the presence of oxidative stress indicators, such as increased malondialdehyde content (MDA), hydrogen peroxide $\left(\mathrm{H}_{2} \mathrm{O}_{2}\right)$ and proline accumulation, with concerning the control [41]. Given the increase in antioxidant activity and the alteration of fatty acids in $S$. himantioides fungus, Wi-Fi radiation could a possible source of oxidative stress

It has been observed that $S$. himantioides exposed to other types of radiation such as ultraviolet radiation, pigments from the culture medium achieved the highest percentages of inhibition for both the DPPH and ABTS assays, compared to total mycelium and culture medium extracts without ultraviolet radiation [18].

Different studies on fungi suggest the use of higher frequency radiation than Wi-Fi (UV-B, UV-C and gamma) [42-46], not only to increase the vitamin D content, but also to improve the chemical and nutritional properties in mushrooms, increases the antioxidant content [42], the appearance [45] and improve their post-harvest qualities [47]. According to the results obtained in this study, Wi-Fi radiation can be used as a possible alternative to improve the nutritional content of edible mushrooms, since an increase in the antioxidant capacity of extracts and ergosterol, a precursor of vitamin D was observed.

\section{CONCLUSION}

The main metabolic changes detected in in vitro cultures of $S$. himantioides exposed to Wi-Fi radiation were described for the first time. S. himantioides increased fatty acids and ergosterol content when exposed to Wi-Fi radiation. This metabolic change effectively defends $S$. himantioides from Wi-Fi radiation through a modification of some of its cell membrane components and an improvement in antioxidant properties. Our data provide guidance for maximized health benefits of mushrooms to potential use as a dietary supplement.
This study should be useful as a reference to understand the changes that occur at the cellular level in the organisms exposed to Wi-Fi radiation. It remains to study the changes that occur at the molecular level to understand the defense mechanism of these organisms.

\section{ACKNOWLEDGEMENTS}

This research was funded by postdoctoral FONDECYT project no. 3180635 and Conicyt PIA/Apoyo CCTE AFB170007. We also thank Victoria Montero for her useful suggestions in experimental design.

Authors declare no conflicts of interest.

\section{REFERENCES}

1. T. Obata, A.R. Fernie, Cell Mol Life Sci. 69, 3225, (2012).

2. G.J. Hyland, Lancet. 356, 1833, (2000).

3. J.H. Kim, J.K. Lee, H.G. Kim, K.B. Kim, K.R. Kim, Biomol. Ther. (Seoul). 27, 265, (2019).

4. K.R. Foster, J.E. Moulder, Health Phys. 105, 561, (2013).

5. J. Friedman, S. Kraus, Y. Hauptman, Y. Schiff, R. Seger, Biochem J. 405 , $559,(2007)$.

6. C. Avendaño, A. Mata, C.A.S Sarmiento, G.F. Doncel, Fertil Steril. 97, 39, (2012).

7. K. Öngel, N. Gümral, F. Özgüner, Cell Membr. Free Radic. Res. 1, 85, (2009).

8. N. Gümral, M. Naziroglu, A. Koyu, K. Ongel, O. Celik, M. Saygin, M. Kahriman, S. Caliskan, M. Kayan, O. Gencel, M. F. Flores-Arce, Biol. Trace Elem. Res.132, 153, (2009).

9. M. Tkalec, K. Malarić, B. Pevalek-Kozlina, Bioelectromagnetics. 26, 185, (2005).

10. D.A. Meloni, M.A. Oliva, C.A. Martinez, J. Cambraia, Environ. Exp. Bot. 49 , 69, (2003).

11. W. Xiujuan, W. Bochu, J. Yi, L. Defang, D. Chuanren, Y. Xiaocheng, A. Sakanishi, Colloids Surf. B Biointerfaces. 27, 59, (2003).

12. H. Costa, S.M. Gallego, M.L. Tomaro, Plant Sci. 162, 939, (2002).

13. M.Farooq, G.S. Babu, R.S. Ray, R.B. Misra, U. Shankar, R.K. Hans, Biochem. Biophys. Res. Commun. 276, 970, (2000).

14. H.X. Ren, Z.L. Wang, X. Chen, Y.L. Zhu, Environ. Exp. Bot. 42, 51, (1999)

15. Y.Y. Su, Y.L. Qi, L. Cai, Mycology. 3, 195, (2012).

16. K.A. Hugues, B. Lawley, K.K. Newsham, Appl. Environ. Microbiol. 69, $1488,(2003)$.

17. A. Fourtouni, Y. Manetas, C. Christias, Can. J. Bot. 76, 2093, (1998).

18. S. Torres, M. González-Ramírez, J. Gavilán, C. Paz, G. Palfner, N. Arnold, J. Fuentealba, J. Becerra, C. Pérez, J.R.Cabrera-Pardo. Appl. Environ. Microbiol. 85, e00870-19, (2019).

19. T. Carlsen, I.B. Engh, C. Decock, M. Rajchenberg, H. Kauserud, Fungal biol. $115,54,(2011)$.

20. P. Aqueveque, T. Anke, O. Sterner, Z. Naturforsch C. J. Biosci. 57, 257, (2002).

21. M. Gill, W. Steglich Pigments of fungi (Macromycetes). In Fortschritte der Chemie organischer Naturstoffe/Progress in the Chemistry of Organic Natural Products, Springer, Vienna, 1987.

22. Y. Chen, Z. Cai, Q. Feng, P. Gao, Y. Yang, X. Bai, B.Q. Tang, Cogent Biol. 5, 1, (2019).

23. A. Shahin-jafari, M. Bayat, M.H. Shahhosseiny, P. Tajik, S. Roudbarmohammadi, Saudi J Biol Sci. 23, 426, (2016).

24. S. Shokri, A. Soltani, M. Kazemi, D. Sardari, F.B. Mofrad, Cell J. 17, 322, (2015).

25. M.L. Soran, M. Stan, Ü. Niinemets, L. Copolovici, J. Plant Physiol. 171, 1436, (2014).

26. K.T. Lim, C. Hu, D.D. Kitts, Food Chem. Toxicology. 39, 229, (2001)

27. N. Nenadis, L.F. Wang, M. Tsimidou, H.Y. Zhang, J. Agric. Food Chem. 52, 4669, (2004)

28. V.L. Singleton, J.A. Rossi, Am. J. Enol. Vitic. 16, 144, (1965).

29. K. Knight, J. Exp. Biol. 217, 1, (2014).

30. M. Suutari, K. Liukkonen, S. Laakso, J Gen Microbiol. 136, 1469, (1990).

31. A. Vian, E. Davies, M. Gendraud, P. Bonnet, Biomed Res. Int. 2016, 1, (2016).

32. S. Banik, S. Bandyopadhyay, S. Ganguly, Bioresour. Technol. 87, 155, (2003).

33. M.H. Gordon FATS|Classification. In Encyclopedia of Food Sciences and Nutrition, Oxford: Academic Press, 2003.

34. U. Krings, R.G. Berger, Food Chem. 149, 10, (2014).

35. A. Teichmann, P.C. Dutta, A. Staffas, M. Jägerstad, LWT Food Sci.Technol. 40, 815, (2007). 
36. V.J. Jasinghe, C.O. Perera, Food chem. 92, 541, (2005).

37. S. Shao, M. Hernandez, J.K. Kramer, D.L. Rinker, R. Tsao, J. Agric. Food Chem. 58, 11616, (2010).

38. J.A. Ko, B.H. Lee, J.S. Lee, H.J. Park, 2008. J. Agric. Food Chem. 56, 3671, (2008)

39. M.S. Calvo, U.S. Babu, L.H. Garthoff, T.O Woods, M. Dreher, G. Hill, S. Nagaraja, Osteoporos Int. 24, 197, (2013).

40. R.R. Simon, J.F. Borzelleca, H.F. De Luca, C.M. Weaver, Food Chem. Toxicol. 56, 278, (2013).

41. H.P. Singh, V.P. Sharma, D.R. Batish, R.K. Kohli, Environ. Monit. Assess. 184, 1813, (2012)
42. S.J. Huang, C.P. Lin, J.L. Mau, Y.S. Li, S.Y. Tsai, Int. J. Med. Mushrooms. 17, 241, (2015).

43. Â. Fernandes, A.L. Antonio, M.B. Oliveira, A. Martins, I.C. Ferreira, Food Chem. 135, 641, (2012).

44. K. Akram, J.H. Kwon, J. Korean Soc. Appl. Biol. Chem. 53, 257, (2010).

45. T. Jiang, M.M. Jahangir, Z. Jiang, X. Lu, T. Ying, Postharvest Biol. Technol. 56, 209, (2010)

46. I. Sommer, H. Schwartz, S. Solar, G. Sontag, J. Agric. Food Chem. 57, 5790, (2009).

47. W. Guan, X. Fan, R. Yan, Postharvest Biol. Technol. 64, 119, (2012). 